\title{
THE SPATIAL “RESPONSE” OF THE TRANSITION: THE CASE OF BULGARIA
}

DOI: http://dx.doi.org/10.18509/GBP.2015.57

UDC: $338.246 .015 .088(497.2)$

\author{
Assoc. Prof. Dr. Stelian Dimitrov \\ Elena Todorova \\ Sofia University “St. Kliment Ohridski”, Bulgaria
}

\begin{abstract}
In this paper we discuss the significant changes and transformations of Bulgaria national space after the collapse of socialist system in 1989, during the so called "transitional period". The transformation covers all aspects of formed social, economic and urban structure of the country, but the most significant changes are in:

- Demographic spatial structure

- Regional disparities (WEST-EAST and NORTH-SOUTH)

- Urban structure and urban centers

These three groups of transformations and their cumulative effect face Bulgaria regional policy in front of new challenges, which need to be addressed in the present and next EU programming period.
\end{abstract}

Keywords: socio-economic changes, spatial transformations, regional disparities, urban development, tendencies

\section{INTRODUCTION}

After the events in 1989 Bulgaria underwent severe changes in terms of political, economic, institutional and fiscal system that led to inversion of the whole mechanism that powered the country. The transition that the country had to surmount refers to every sphere of everyday life, which is why the changes that happened overnight will echo in the overall socio-economic situation of the country for generations to come. This paper will not look into the complexity of the process in terms of its economic, social or psychological side, but will elaborate on the spatial aspect of the changes in the period 1989-2014 and will examine the spatial projection of the dramatic demographic and economic changes and the reason for the disparities that rupture the country. The research is based on analysis of official statistical information, examination of scientific papers on the topic and terrain studies on the territorial units in the country. The Geographic Information Systems are used as major tool for processing and analyzing the statistical data and generation of the information.

In 2014 Bulgaria is a member state of the European Union that experiences serious demographic problems, economic instability and dependency on external support. The Bulgarian villages and the smaller towns are depopulated as the population concentrates in the cities or simply emigrates. The agriculture slowly dies under the constant attacks of cheaper import products and the low competitiveness of the sector. The industries have a hard time to regenerate after the inexpedient privatization process. The R\&D sector is yet to develop. The unsustainable management of tourism development leads to the low 
part of the GDP it sustains. All in all the country is struggling to catch up with the European standards, without referring to its own specific problems. And they are to a great extent the consequence of the transition period.

In addition to political and economic issues and problems, the Bulgarian national space has been heavily affected by absence of adequate regional policy and problematic legislative framework in the field of territorial development. After 2004 Bulgaria has adopted 3 Regional development acts, but only the last one (2012) is aiming at establishing the necessary logical links with the Spatial development Act, elaborated in 2006. As result, the regional development and its regional development policies were more like "wish lists", without any spatial projection, and Spatial development plans were driven only by economic interests of the investors, lacking the necessary public policy fundament.

As major result of the cumulative interactions of these economic, demographic, legislative and policy-related problems, the Bulgarian national space has been affected by dramatic regional disparities, some of which are described below.

The population back in 1989 amounted $8989476^{51}$ people, which means that for the last 25 years it records $15,74 \%$ decrease with constant trend through the years. The decrease is ubiquitous for the territory of the country, but the regions with most preserved demographic trends are situated in South Bulgaria. Only Sofia (capital) and Varna districts increase in population. The most depopulated regions are located in north west Bulgaria. In north Bulgaria live $38,1 \%$ of the population, most of which is concentrated in its eastern part.

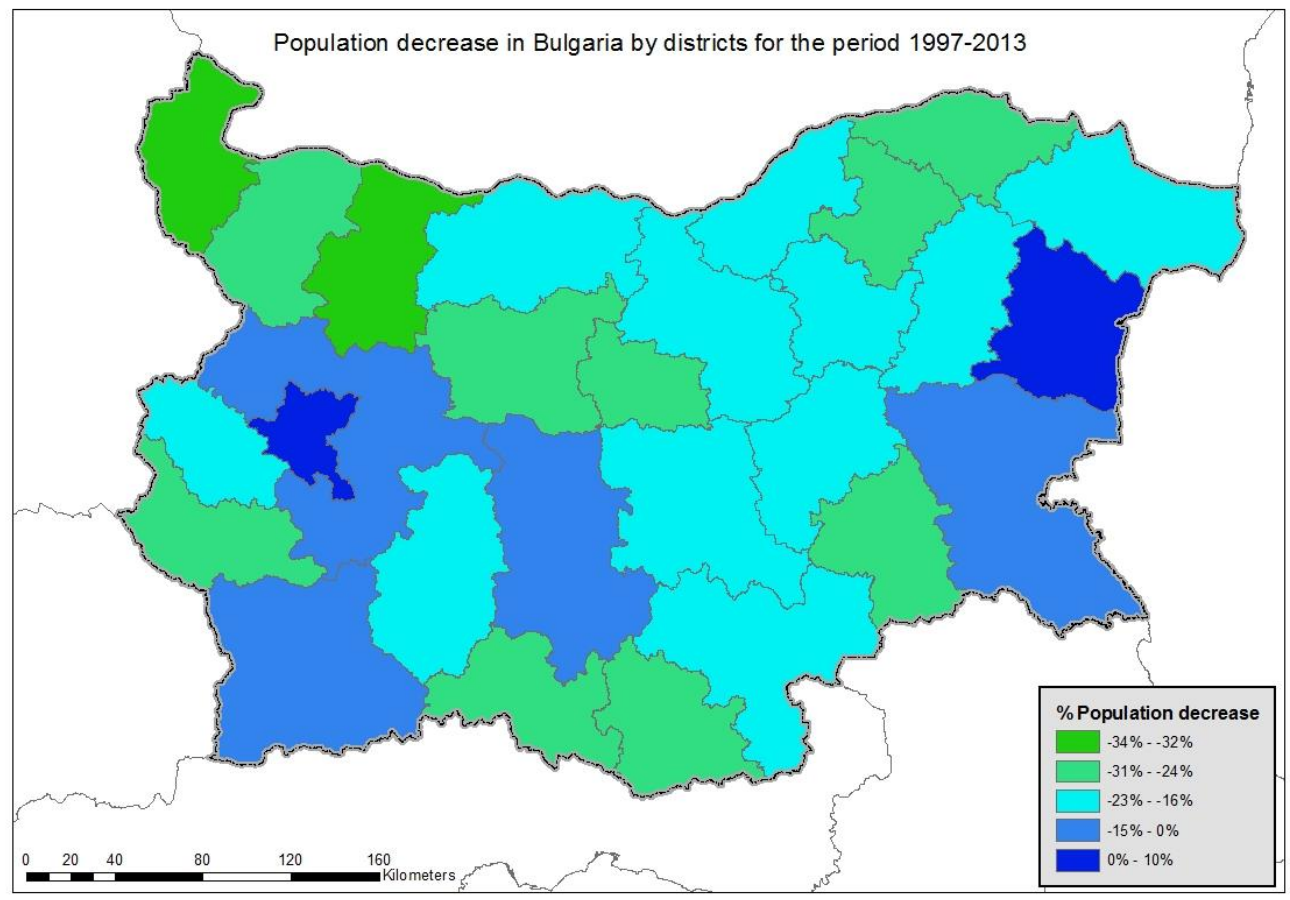

Figure 1 Population decrease in Bulgaria by districts for the period 1997-2013

(Source of information: National Statistical Institute)

The decrease of population for the period 1997-2013 in south Bulgaria is 8,34\%, while north Bulgaria lost $19,28 \%$ of its population. The great disparities, generated in such small

${ }^{51}$ All data is provided by the National Statistical Institute, if not pointed otherwise. 
territory happened for a reason. The great isolation that north, and mostly north-west Bulgaria suffers in terms of transportation connections is one of this reasons. The poorly developed relations with the R. Serbia and the lack of intermodal transport to the north pose the region in isolation from the north and west. The orographic barrier to the south blocks the fast connection to the capital and the spread of its influence in that direction. And the influence of Sofia, as a great economic centre, reaches far beyond its direct hinterland and gives a great push to the development of the whole south-west region. The industries that were the driving force of the South-west until 1990 were all lost.

These problems have been accumulated for years. Until 1990 Bulgaria exhibited typical demographic trend from rural to urban areas. In 1988 13,5\% of the migrations moved from the city to the villages, and $35,1 \%$ - in the opposite direction. Later on, after the changes, with the decrease in production in the state enterprises, this trend has been reversed with a shift in population from the urban to the rural areas in five of the nine districts and with all districts showing decreases in urban population. ${ }^{52}[1]$ The unemployment in that period escalated form 1,8\% in 1990 to $16.2 \%$ in 1993. According to OECD Economic Surveys: Bulgaria 1997, the poverty and hardship for the population increased each year - the infant mortality rate increased, the number of yearly reported crimes more than tripled in the 1990s, relative to 1980s, the average real wages continued decreasing until 1996. Moreover, the polarisation in the distribution of income and wealth deepened with low income and high unemployment concentrated in depressed "Smokestack" industrial regions, some agricultural regions and areas with high concentration of ethnic minorities. [2]

All this circumstances caused dynamic movement of the population, resulting mainly in emigration of young and educated people to the western countries. This, along with the deteriorated age structure of the population led to drastic decrease of its number and irretrievable demographic problems. The spatial distribution of these phenomena is closely related to the economic profile of the regions and the closure of all the manufacturing facilities that gave jobs to whole towns and the failure to reorganize the agriculture into a perspective branch of the economy. According to World Bank (2001) report Bulgaria: The Dual Challenge of Transition and Accession "Unemployment in Bulgaria has also a regional dimension, with a dispersion in the unemployment rates across regions that is both increasing and persistent. Regional unemployment unbalances across regions are comparable to that observed in most European countries. More important, however, is the fact that regional unemployment is rising even when total unemployment is falling. Further, such disparities appear also to be persistent, with the standardized ranking of regions being very stable over time"..[3] This, together with the changed needs of the population towards better education, public services and living standards, directed the people to the big cities that offered more opportunities.

The economy of the country also suffered a great turmoil. By 1992 GDP contracted with $25 \%$ of its 1989 level and by 1997 dropped to $63 \%$ of its 1989 level. Until 1997 the economic situation of the country was very unstable, characterized with high and variable inflation, slow restructuring, unemployment, economic crisis. ${ }^{53}$ [4] The structure of the economy underwent serious changes, especially in terms of agriculture, where mainly the

\footnotetext{
${ }^{52}$ LEVINSON, ALFRED Bulgaria's Transition to a Market Economy, pp.107-108

${ }^{53}$ Mihov, Ilian, The Economic Transition in Bulgaria1989-1999, INSEAD, 1999, pp. 5-16
} 
grain production is still winning. In 1992 it substituted $12 \%$ of the gross value added, keeping this percentage in 2001, and dropping down to 5\% in 2011.
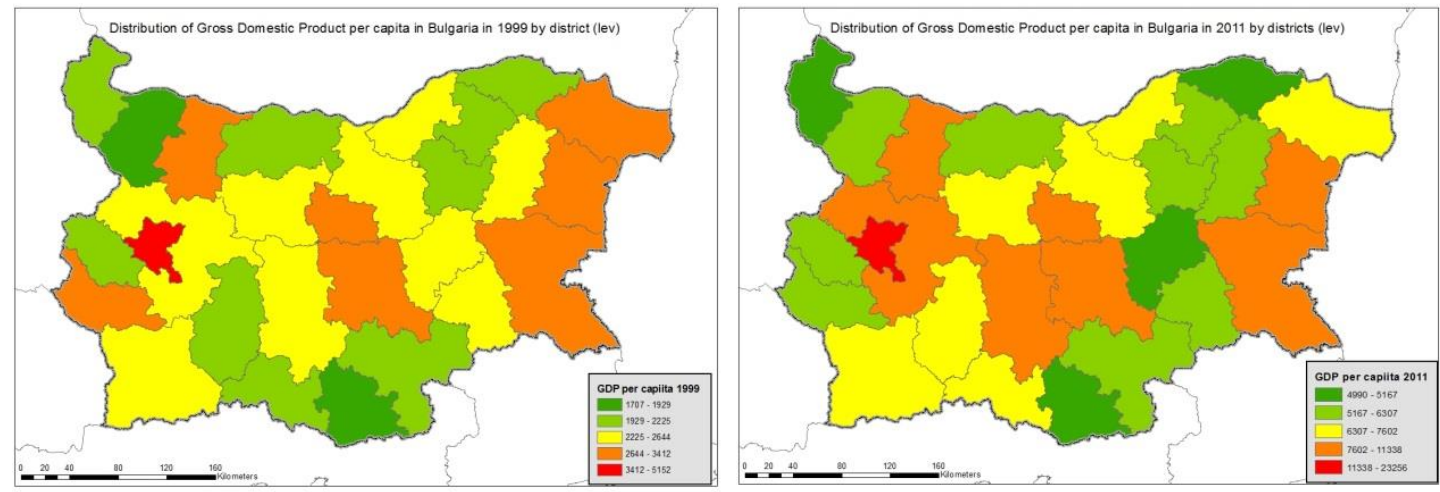

Figure 2 Distribution of Gross Domestic Product per capita in Bulgaria in 1999 and 2011 by districts (lev) (Source of information: National Statistical Institute)

The spatial distribution shows that the polarization started after 1989 deteriorates, as seen on Figure 2. While in 1999 most of the districts generate the average GDP per capita, in 2011 the contrasts escalate as the number of districts below and above average rises. In 2012, north Bulgaria forms 25\% from the national GDP, which once again confirms the great disparities between the north and the south.

The local economies try to compensate the closure of branch-plants with microenterprises that try to fill in the newly formed economic niche, but the lack of enough experience and finances usually results in feeble microenterprises that rarely withstand the economic distresses and are hardly a market factor. The incapability to draw investments and harness the prolific local resources into sustainable, well-built, self-sustaining and profitable business that forms the profile of the local economy is the consequence of the chaos in the state apparatus in the years after 1989. Furthermore, the last 25 years are accompanied with a great technological revolution that imposes new ways and new players in the world economy and calls for a quick adaptation from the local economies that are still being regenerated. All these processes go with the social problems that only accelerate those we already mentioned - the lack of adequate educational, health, pension and social reforms, along with the demographic collapse creates an unstable and unhealthy social environment.

Following the Poverty and Social inclusion indicators (NSI), measured by the National Statistical Institute, the relative share of the poor in Bulgaria in 2013 is $21 \%$. The indicator keeps its overall level since 2006.

According to the UNDP Millennium Development Goals 2008[5] "Territorial disparities continue to hold up Bulgaria's overall economic growth...The share of the poor by municipalities varies from $1.8 \%$ in the capital Sofia to $53.8 \%$ in the municipality of Boynitza, Vidin district. There are salient differences between urban and rural poverty. Urban poverty has to do with money, whereas rural poverty is about no jobs, poor or inaccessible healthcare, education and social services. Natural consumption in the villages continues to account for a significant share of total consumption at the expense of income from wages or entrepreneurship." These trends continue nowadays.

Based on this analysis, we have made an attempt to categorize the regions in the country in groups by their current level of development and specific problems, using as a base the administrative unit district as a most appropriate in its territorial scope. 
The first region that most evidently stands out is Sofia capital. It is alone in its group as a single centre that concentrates investments, infrastructure, social educational and administrative services, human capital, stands out with viral and dynamic environment that creates opportunities and therefore serves as a point of attraction of the demographic and economic potential of the country. For the period 1997-2013 the number of population of the district rose with $10 \%$, and this is what the official statistic says. The dynamic development in the capital is a breath of fresh air for the economy of the country. But on the other hand, it robes away the human capital and the investments from the regions lagging behind and thus forms a monocentric development, which in this case is not a sustainable structure.

The second group of districts we can call the Sofia hinterland, which is formed from these districts that are under the direct influence of the capital and have good transport connections that ease the transfer of goods, people and capital. These districts are Sofia, Pernik, Blagoevgrad, Kjustendil.

The third group covers the big cities that have slower temps of development than the capital, but are a factor that concentrates people and capital and are a distinctive leading force for the whole district. These are Burgas, Plovdiv and Varna. Burgas and Varna are certainly one step ahead of Plovdiv, as their geographic and transport location gives them opportunities for development of more diversive economies.

The fourth group includes the decaying centres - the cities that were once thriving, but are now losing their population and are resting on industries that sustain a medium living standard for the population. These centres have a hard time attracting investors and creating a good business environment. Most of these districts used to have an agricultural profile of the economy in the past. Generally they are characterized with concentration of the population in the cities and strong depopulation of their rural parts. Such cities are Pleven, Veliko Tarnovo, Gabrovo, Lovech, Rousse, Razgrad, Silistra, Dobrich, Targovishte, Shumen, Kardzhali, Pazardzhik, Smolyan, Haskovo, Sliven, Yambol and Stara Zagora. Some of the districts show deviation from the common demographic indicators, which are mainly due to the specifics of the ethnic structure of the population. The last group may be summed up as the North West, comprising three disricts: Vidin, Montana and Vratsa. Earlier, we discussed the main problems of the region, related to its isolation. It remains the less developed and less perspective region in the country and in Europe as well. Its capacity for self-regeneration has been exhausted long ago, and therefore it needs external support to rediscover its competitive advantages and make a fresh start.

\section{DISCUSSION}

This informal attempt of territorial categorization does not mean to set boundaries and to give labels. It comes to show that the regions have different problems and specific needs that need to be addressed by the national regional policy.

The organization of the national space, built for so many years following a certain doctrine had to be drastically rearranged to serve a new economy with completely new rules. The foundation that the economy, society and infrastructure had to step on was not effectively used. It was actually ruined, because it was part of old ideas and a result of another time that was quickly condemned as wrong. The process of adaptation was chaotic, misunderstood and disoriented and therefore - not effective. The problems the 
country and its regions experience are deteriorating, which means that the regional policy has to reverse its starting point to the specificity of the regions and their individual needs.

\section{REFERENCES}

[1]Levinson, Alfred Bulgaria's Transition to a Market Economy, pp.107-108

[2]Mihov, Ilian, The Economic Transition in Bulgaria 1989-1999, INSEAD, 1999, pp. 516

[3]National Statistical Institute

[4]OECD Economic Surveys: Bulgaria 1997, pp. 35

[5]UNDP (2008). Millennium Development Goals: Bulgaria. Sofia, pp. 13

[6]World Bank (2001) Bulgaria: The Dual Challenge of Transition and Accession. Washington, DC, pp. 82 